\title{
Method and Expansion of Contemporary Textile Embellishment in Nigeria
}

\author{
Adiji Bolajoko Esther \\ Federal university of technology, Akure, Industrial Design Department, P. O Box 704,Akure, Ondo state, \\ Nigeria
}

\begin{abstract}
This study has dealt into the technique and development of handcrafted dyed and printed textiles in SouthWestern Nigeria, using Abeokuta, Oshogbo and Akure as study areas. The study looked into the modern development and decoration of handcrafted dyed and printed fabrics among various strata of the society. It examined the techniques in use and ascertained its development to modern fabric decoration. Questionnaire was distributed to the producers, traders of these crafts and consumers. In all, handcrafted textile technology is one of the oldest craft that still plays a prominent role in the contemporary times in the social economic life of Nigerians and still provide a good basis at solving the dangerous trend created by unemployment in the society.
\end{abstract}

Keywords: Handcrafted, embellishment, technology, fabrics, processing

Publication date:September $30^{\text {th }} 2020$

DOI: $10.7176 / \mathrm{ADS} / 85-05$

\section{BACKGROUND}

Nigeria is well known for her cultural and artistic traditions, and has remained vibrant in the face of rapid urban growth and increasing influence of the western culture and economic institutions. Despite the homogenizing trends, tourists visiting Nigeria are stricken by breathe, taking varieties of dyed and printed fabrics used for day to day cloths of her inhabitants.

The dress of a given individual from one day to the next is generally mixed between western attire and indigenous dye has a long tradition. Cordwell (1979) observed that batik still remain the favorite clothe for men and women. This made it possible for the clothes to bear political or commemorative motifs used in Nigeria, during occasions and ceremonies such as coronations house warming naming ceremonies and so on.

There are innumerable crafts practiced in different part of the world today, Nigeria is not an exception. Medap (1980) observed that the art of dyed and printed fabric began after the early man had started looking for protection by weaving mats for self and family. The early man had left the cave and started to grow cotton and made woolen threads, which were extracted, from plants and animals. At this time, clothes woven from these products were used plain, to cover the body as replacement for animal skins earlier used. Brown (1979) informed that, indigo, the most famous of all dyes in West Africa, particularly in Nigeria, is also the world oldest dye and most important dye stuff. Indigo dye is still used today where the villages have flair for dyeing cotton yardage for traditional clothing of the people. De Negri(1996) noted the ancient immigrants might have brought the art of dyeing from decaying empires of the desert such as Mali, where large scale cotton industry existed in the $4^{\text {th }}$ century.

Traditionally, the idea of dyeing and printing fabrics was accidental through the resist method. Medap (1980) insisted that some dyers developed their skills from the use of plain fabrics to the dyed types through experimentation. Some of the fabrics that were to be dyed the following day were rumpled by some members of the family and dumped in the dye bath. This led to a new discovery of marbling effect which represents a wide range of textile methods common in west Africa and a great range of beauty in colour, texture and vibrant designs.

Nigeria has a love for natural fabrics and in south western region they have special interest in pattern and designs with many prints and motifs. However traditional methods of dyeing fabrics are threatened by cheap imports from abroad. In Nigeria today, textile manufacturing is a key local industry, supported by a chain of suppliers such as cotton growers and natural dye makers. In Northern region it is common for cloth to be in single colour especially indigo colour. Dyers use dye pits of 2-3meters deep in south western Nigeria, while in the Northern part of Nigeria the dye pit is between 1-6 meters deep, the cloth left in these pits for a day or two before being rinsed and dried. Sometimes, indigo cloth is beaten with a beater to give it extra sheen. Across the south western region, bright colours and patterns are popular. These are created using various techniques which keep some of the form being dyed, so that the pattern appears in white or a lighter shade. Pattern dyed cloth in south western region is known as adire in Yoruba, small stones or pebbles, seeds can be tied into cloth to create small patches which are not dyed. Sometimes, cloth can be dyed by pinching up sections of the material with raffia or thread. Resistant substance such as cassava starch, wax can be added to the cloth, these resist any colour when dyes are applied. Sometimes, metal stencils are used when dye is applied by hand. In some parts of Nigeria, special garments are made from strips of woven cloths known as aso-oke in Yoruba region, when weavers are 
often commission to make a special pattern for certain families or occasion. But the work of local dyers, weavers, and textile mills are threatened by the growing fashion for wearing western styles or second hand clothes, even when Nigerians choose to wear traditional outfits as they often do on Sundays or special occasions, they buy cheaper machine made clothes imported from Asia which copy popular Nigerian designs, and sometimes falsely claim they are made in Nigeria.

Industry experts hope in the future better enforcement of trading laws and impounding of illegal imports will give local traders a better chance of surviving and thriving. Akintayo (2001)stated that traditionally, the indigene of osogbo were dyers and weavers, but the entire people of osun state in particular were said to be the best, so much that there is a sayiny that aro nbe in osogbo, omo enia nbe ni ibadan. That means, osogbo is only known for as a home of good dyeing, but Ibadan is a highly populated city. Adiji (2006) mentioned that today, Abeokuta has become a prominent center of textile crafts; much textile craftwork is done at Ibadan and osogbo towns of south western Nigeria. Evidence showed that adire was a device for making use of old woven materials known as kijipa. In some cases yarn were pre-dyed and woven into pattern, sometimes the entire fabric was dyed. White fabrics were also decorated by direct printing technique that utilized carved wood or other printing materials Oyelola (1981) opines that, even today, indigo dyed cloth is still being used by the Hausa and Tiv weavers. It is used as one of the most prestigious cloth of the Yorubas called "etu", a cloth considered as one of the prestigious materials used for weddings burials and so on. The thread is dyed before weaving.

Piction (1995) claimed that, European traders introduced batik as a traditional technique from Java, Indonesia, in where resist is applied manually. Since consumers are very comfortable with the designs, the producers learn the techniques. Since the discovery of synthetic dyes, the ability to transform everyday white cotton into prized deep blue increased, and a highly valued skill was passed on by specialist dyers from generation to generation.

From Abeokuta in Ogun State to Kano in Kano State of Northern Nigeria, Indigo dye signified wealth, abundance and fertility. Incidentally, women are more involved in indigo dyeing in most towns in Yoruba land. They exhibit a lot of expertise in this direction. The Oshogbo dyers pay tribute to patron deity, "Iya Mapo" to ensure the success of the complex dye process. Clarke (2003) noted that, among the Hausas, where the export trade is prestigious, textiles were highly organized. Male dyers working at a communal dye pit were the bases of the wealth of the ancient city of Kano. While the spiritual realm is an important dimension of cloth production, dyeing was in itself and important business at which high degrees of specialist skill was developed in centers such as Abeokuta, Oshogbo, Kano and Ibadan. Among the roles fabric has played in the past in Nigeria's culture is that, it has acted as a medium of exchange. Perani et al (1969) note that, in Western Nigeria, among the Yoruba people, stripes of cloth were normally standardized and there would therefore be a regular number of such stripes of a standard length needed to make a woman's wrapper. This would become the unit of value with smaller transaction paid for a roll of cloth as it came from the loom.

Aremu (1982) establishes that handcrafted textiles are characterized by a wide variety of distinctive local styles and traditions. This localized pattern of stylistic development had two apparent contradictory impacts on issues of personal and group identity. ON the other hand, it contributed to the development of motions of localized group identity, as people of a particular area are often dressed in a distinctive cloth design allowing them to be readily distinguished from strangers and travelers. This according to him, assisted in the formation of a sense of tribal or ethnic identity in the colonial period. Textile forms were considered among the cultural resources available for the construction of a new dimension in group identity.

\section{COTTAGE PRODUCTION AND PROCESSING OF DYED AND PRINTED TEXTILES}

Textile cottage industries have been in existence in Nigeria for many years. The materials were home-made as they are manually produced and hence, limited in quantity and production output. This factor is common to the resist dye craft and hand-printed textiles. The practitioners are indigenes in their individual respective locations. Resist dyeing is a process of withholding some particular areas of the fabrics to prevent dye from reaching designated areas. In the South-Western Nigeria, dyeing is practiced in most Yoruba towns and villages, the large dye pots of the earthenware are a characteristic feature of every compound. The chief dyeing centres in the Southern Western part of the country are Abeokuta, Ibadan, and Osogbo. In these areas, where the cloth has assumed the popular name of "Adire" means "to take, to tie and dye". The women have developed this craft to a state of excellence.

Akintayo, (2001) Observes that, there was a small range of locally produced plant dyes that allowed weavers or dyers to produce a few shades of colours. The author further explained that there are a number of techniques used to decorate clothe after it has been woven. Most of these techniques have their origins in the indigenous weaving industries, but have later been applied to the decoration of imported fabrics.

Cottage dyers have utilized a variety of methods of resist dyeing. The main method of decorating fabrics or embellishing fabrics is the dyeing of threads or completed cloths, which produced pattern effects on the threads 
and cloths by varying the colours of threads used. These dyers include the Yoruba in Southern West Nigeria and a number of traditions that utilized starch, wax, or tie-dye of which the Adire of the Yoruba is best known.

Ojo, (1994) stresses that; the craft of batik was development on traditional adire eleko, which has witnessed different changes in the history of dyeing in Yoruba land. He stated further that, this history could have remained nothing to write about, if not because of the Federal Government of Nigeria's restrictions of Textile imports. The restriction, more importantly on clothing materials was said to have forced Nigerians to revive the art of making batik cloths. Batik technique in the present day has developed to an enviable standard. One of the many ways of decorating cloth is through this technique. By definition, batik is an Indonesian method of decorating textiles by coating the parts not to be dyed with wax. Ojo,(Ibid;) explains further that, there are variations of colour combination in the founding countries complicated patterns that are quite different from Nigerian batik style, which is often dyed in indigo blue.

Any cotton fabric that will absorb dye stuff is ideal for batik dyeing. The weave of the cloth should not be too close and the fabric should be translucent when held in front of light. Oguntona, (1986) explains "that, it is difficult to say specifically the origin of the kind of art.

The development created by traditional resist method paved way for other types of resist mordant to reach the Nigerian craftsman. By this, the batik method was made popular. Here the wax is melted and an instrument known as Tjanting is used to apply the wax to a predetermined area to resist such areas from dye contact.

Batik however, has become internationalized that the practice covers a wide spectrum, while tie-dye, a resist technique in which pattern is created by a process that protects areas of fabric from penetration of dyes. One property a resist must have is not to dissolve in the bath. It must be removable after dyeing. This pattern could be formed by tying, knotting folding, or by sewing some areas so that dye cannot penetrate. Other areas are either left free or loosely held so that they can retain the colour.

Printed textile on the other hand, is produced with the usage of coloured pattern on fabric surfaces, Textile printing is a localized form of dyeing, in which the cloth is coloured not by immersion in the dye bath, but by applying the dye or mordant in a thickened paste form on the surface Oguntona, (1986) claims that the dye is absorbed into the fabric with the help of steaming or wet development process. Production of coloured pattern on textile by any means, other than dyeing in, weaving, mixing coloured threads in known as printing. Handcrafted printing is equally divided into various techniques. For example, block printing, screen printing and stamping method etc. which is done by hand, is carried out by a block of wood on which design is carried in relief. A separate block is required for each different colour in the finished design. The colour is applied to the raised part and then transferred to cloth by stamping the block on it with wax or printing ink. This is the oldest method of printing, although it is slow, expensive, but requires skilled labour.

\section{METHOD TO CONTEMPORARY FABRICS DECOROATION}

The respondents agreed that there are abundant raw materials for producers to utilize for handcrafted textile with new development to modern fabric making. This development and agreement is highlighted in table 1.4 below with an average mean score of 2.53. the problem according to respondents of handcrafted dyed and printed textiles is that, they have little knowledge of how the dyestuffs and other production materials such as yarn, caustic soda and hydro sulphate are made. The researcher is of the view that local production techniques are adequate except that the bulk populations of the producers are semi-literates who have less knowledge of the chemistry of their materials and have little ideas about quality control procedures to determine the acceptable standard of woven fabrics.

They seem to believe that the educational programmes for training the up-coming dyed and printed textile producers are inadequate in the educational institutions with an average mean score of 2.53. this assertion might not be correct, because the researcher's experience in the educational sector shows that their training is adequate, except for the inadequacy of facilities. This has to be improved so as to produce excellent manufacturers. This also is highlighted in table 1. an average mean score of 3.42 translating to the fact that traders in table 1 . below strongly agreed that, they would report back to producers the customers complaints if need be on the production quality, but they emphasized further that the materials on sale have three different quality grades depending on the purchase capacity of the quality of the fabric from the factory and the locally spun yarn common among the Owo traditional dyers. 
Table 1. Producer's responses to the techniques in use and ascertain its development to modern fabric decoration.

\begin{tabular}{|c|c|c|c|c|c|c|c|}
\hline \multirow[t]{2}{*}{ Variable } & \multicolumn{5}{|c|}{$\begin{array}{c}\text { No of respondents } \\
\text { scoring }\end{array}$} & \multirow[t]{2}{*}{$\begin{array}{c}\text { Average } \\
\text { mean score }\end{array}$} & \multirow[t]{2}{*}{ Percentage } \\
\hline & 4 & 3 & 2 & 1 & 0 & & \\
\hline $\begin{array}{l}\text { Despite the abundant resources in terms of raw } \\
\text { materials, producers lack the intellectual skill to cope } \\
\text { with complexities of preparing successful handcrafted } \\
\text { dyed and printed textiles. }\end{array}$ & 13 & 44 & 14 & 21 & 0 & 2.53 & 47.8 \\
\hline $\begin{array}{l}\text { The educational programme available in South- } \\
\text { Western Nigeria is inadequate }\end{array}$ & 24 & 33 & 4 & 30 & 1 & 2.53 & 47.8 \\
\hline
\end{tabular}

Source: Fieldwork 2005.

The field survey indicates that handcrafted and printed textiles have equal claims of survival and patronage if it can be made to meet the test of time locally and internationally.

Table 2. Trader's responses to the techniques in use and ascertain its development to modern fabric decoration

\begin{tabular}{l} 
Variable \\
\hline
\end{tabular}

\section{Source: fieldwork 2005}

The consumers agreed with a lot of commitments on the side of producers, handcrafted dyed and printed textiles can go a long way for local consumption and exporting of the goods.

The researcher extended a discussion with a producer who now engaged in petty trading. She informed the researcher that, the commercially built textile industries also gave handcrafted printed textile technique a very big blow. With the inception of these factories, Nigerians are no more interested in buying the printed fabrics. With careful observation, the traits of tie-dye as a method could be seen in the textiles fabrics produced by the factories.

The products from factories according to the producers guarantees no fast colours, as they also become stale quickly while locally produced fabrics do not stale easily because the indigo colour is potent and fresh. The researcher observed that if Nigerians are given the opportunity to explore the technique very well, the products will have a chance to survive.

Much have been said on the establishment of dyed and printed textiles the supporting trend of event that the method of handcrafted arts find its way into the hands of practicing artist through the first innovation which came when the Mbari Mbayo workshop stepped into the production of printed and dyed textiles. Adiji (2006), mentioned the techniques they use are generally the same, but the most popular of their dyeing is that of the traditional aso-oke called "ofi". The technique involves the tying of yarns in several lengths of different colour at intervals, also weavers in the town use shade of colours that may be obtained from indigo.

\section{CONCLUSION}

The researcher noted that, technically, the problem of hardship in production was seriously reduced with the development of various machines for making prints in mass. Producers now have the opportunity to pass through formal education, learn more techniques and use traditional motifs to achieve their aims. Technology development appears to be extensive, and sophisticated. The developed technologies involved in making of 
textile fabrics in Nigeria are given a priority attention by textile designers, so as to provide affordable and suitable for consumers.

\section{REFERENCE}

Adiji, B.E (2006), Assessment of Handcrafted, Dyed and Printed Textiles in Selected Cities in South Western Nigeria. Unpublished M.Tech Thesis, Federal University of Technology, Akure.

Brown R (1979), The Weaving, Spinning and Dyeing Book Published by Routledge Kegan Paul Ltd, London pp245-246

Boone, C (1992) Merchant capital and the roots of state power in Senegal; 1930-1985.New York Cambridge University Press(HTML DOC) PP15

Eicher,J.B.(1976), Nigerian handcrafted textiles .Published by university of ife Press, ile ife. Pp32-53

Filani, O (1999), Trends and experiments on improvision of Arts materials in Nigeria; Recycling from Waste to Wealth. Journal of Industrial Design and Technology(JINDEST) VOL I, PP 24-27

Kaufman, G and Johnston, M.P(1967), Design on Fabrics. Published by Van-Nostrand Reinhold co. New York . NY 1000.pp9

Kparevzua, B.A(1990) The role of Design in a Technological age Nigerian Society For Education through Art.(NSEA) Journal of Art Education vol ii, pp 174

Ogunduyile S.R (2006) Cottage textiles production; A step out of poverty. Inaugural Lecture, series 41. Delivered at federal university of technology, Akure.

Onu, O (1989) Reort of techno-economic Survey on textiles, weaving Apparel and Leather, Supplementary on carpet, sub-sector and Recommended Projects.

By Multi-Disciplinary Task Force. Vol.ii \& iii. Pp19-28. 